\title{
An Investigation of Workplace Environment in Karachi Textile Industry towards Emotional Health
}

\author{
Nawaz Ahmad ${ }^{1}$ \\ Sherbaz $\mathrm{Khan}^{2}$ \\ Faizan $\mathrm{Ali}^{3}$

\begin{abstract}
The research investigates the Workplace Environment in Karachi Textile Industry towards Emotional Health. The paper utilizes Multiple Regression model to observe the internal environment of textile industry as well as for the implementation of healthful environment for the workers of textile at this time in Karachi. Primary data was collected by questionnaires circulated in four different textile companies, two local and two multinational. This paper also studies the impacts of light, temperature, noise and emotional effects on employees and on their daily life. The result revealed that among all factors health safety is the core element that is affecting on Job Satisfaction and required more deliberate.
\end{abstract}

Keywords: Investigation Workplace, emotional health, physical health, organizational environment, Industry comfort level in Karachi textile Industry.

\section{INTRODUCTION}

\section{Background of the Study}

Pakistan is one of the world's leading cotton producers. The contribution of this industry is $8.5 \%$ of GDP of Pakistan, and also it provides employment to 15 million people, therefore, the importance of this industry towards economic growth of country cannot be denied (Ghulam Muhammad,Ubedullah Memon, 2012). Being a market leader, the textile industry should provide a working environment which is safe, comfortable and friendly for all concerned especially for employees in order to enhance productivity and quality and also to maintain its position. Productivity and quality can be influenced by ergonomics considerations. Ergonomics is all about studying how to improve of workplace and the employees who perform that work" (Ertugrul Tarcan and Ergin Sait Varol, 2004) (Feare, T, 2001). In other words, "Ergonomics work places designed to permit and to encourage the person to make the best use of his or her abilities" (Makhbul, Zafir Mohd, 2013).

Ergonomics study plays an important role for the betterment of that organization. If the employees are satisfied with their workplace then efficiency level and loyalty of employees towards the organization is increased. This loyalty leads to prosperity of that organization (Ertugrul Tarcan and Ergin Sait Varol, 2004). Improved working conditions are directly related to productivity, quality and occupational health and safety (Paul H.P. Yeow. Rabindra Nath Sen, 2003).workplace ergonomics such as indoor air quality, Lightening, buildings general environment, Acoustics and furniture and tools modify worker's satisfaction and as a consequence his performance and loyalty (Makhbul, Zafir Mohd, 2013). As far as poor workplace conditions are concerned, they can result health complaints including depression,

\footnotetext{
${ }^{1}$ Assistant Professor, IoBM, Karachi

${ }^{2}$ Associate editor, SZABIST

3 Masters Student, Indus University, Karachi

\begin{tabular}{llll|l}
\hline JISR-MSSE & Volume 14 & Number 1 & Jan-June 2016 & 63
\end{tabular}
}


stress and work related fatigue. People doing high strain jobs (Which are characterized by high demands i.e. lack of opportunities to make decisions concerning the job) are more prone to have high blood pressure and other, health related problem, whereas, people doing low strain jobs (Which are characterized by low demands and more control have lower than average number of health complaints (Annet $\mathrm{H}$ de Lange, Toon W Taris, Michiel AJ Kompier, Irene LD Houtman, Paulien M Bongers, 2002).

Stress can be defined as "response to challenging events or an environmental characteristic which poses a threat to individual". Job related stress results lowered productivity and lowered physical and emotional health of employs. It mainly depends on factors like poor working conditions and work overload, role in organization, career development, poor relationship at workplaces (Jagdish K.Dua, 1994). Work Related fatigue can cause health complaints like sleep problems and stress. This can decline activity level of employees. Prolonged fatigue may also lead to chronic diseases like depression, rheumatoid diseases etc. (J K Sluiter. E M de Croon, T F Meijman, M H W Frings-Dresen, 2003). Work experience and employee's emotional health can be correlated. Positive work experiences and positive emotional responses influence individual wellbeing outcomes. Adverse work experiences are responsible for negative employee emotional responses (Peter Cotton, Peter M. HART, 2003).

\section{Hypothesis}

To fulfill the research objectives and based on the literature review done, the researchers have Developed five hypotheses which are:

H1. There is a significant relationship between indoor air quality of the organizations and the health complaints from the employees.

H2. There is a significant relationship between lighting of the organizations and the health Complaints from the employees.

H3. There is a significant relationship between furniture and tools provided by the Organizations and the health complaints from the employees.

H4. There is a significant relationship between acoustics of the organizations and the health complaints from the employees.

H5. There is a significant relationship between building's general environment of the organizations and the health complaints from the employees.

\section{Problem Statement}

The research aims at the Investigation of Workplace Environment in Karachi Textile Industry towards Emotional Health. The main objective of this study is to observe the importance of workplace Environment for Emotional Healt in the industry of Textile with special reference to Karachi, Pakistan. And specific objectives are transformed in to hypothes. The present study is conducted to shows that the internal environment of textile industry and for the implementation of healthful environment for the workers of textile here in Karachi. Also with

\begin{tabular}{l|llll}
\hline 64 & Jan-June 2016 & Volume 14 & Number 1 & JISR-MSSE
\end{tabular}


the help of this survey we can take corrective actions for the betterment of employee health for work environment. Hence the research focuses to observe the impacts of light, temperature, noise and emotional effects on employees and on its daily life.

\section{LITERATURE REVIEW}

\section{Indoor Air Quality}

Good Indoor Air Quality has a significant effect not only on worker's health complaints but also on their job performance (Dalbokova, D. and Krzyzanowski, M, 2002) (Ertugrul Tarcan and Ergin Sait Varol, 2004). A good Indoor Air Quality improves production qualities and helps to increase worker's productivity by maintaining a healthful working environment (Martin, J., 1999). Whereas poor Indoor Air Quality declines the performance level of employs and as consequence has adverse effect on the economy of industry. It is also related to health problems of employee. Organizational commitment and engagement that differentiates it comes to human behavior and commitment to their organization, and it could be argued that the involvement of not only healing. The degree to which a person is aware of his work and absorbed in the performance of their duties. In addition, The OCB include volunteering and informal behaviors that can help coworkers and organization, the performance obligation approach paper instead of a purely formal role additional voluntary Code of Conduct. (Saks, 2006)."

Commitment to attract more closely related to the construction work and "flowing". Job involvement is defined as "a belief or cognitive state of psychological identification. This differs from the commitment, which is more concerned with how their individual / her own performance work during his / her work. Six areas of work life lead to exhaustion or engagement. They argue that labor participation is associated with stable load, emotions and control the selection of the appropriate recognition and reward, community support, employment, equity and justice, and meaningful and valuable work. Like burnout, it is expected that the commitment of the six factors mediating the relationship between work life and different outcomes (Maslachet al 2001)."

Public perception "meaning" in connection with work related to different levels of commitment and, ultimately, performance. Employees are actively seeking meaning through work, and as long as the organizations try to provide a sense of meaning, employees are likely to quit. The survey results suggest that many people feel a greater sense of job search $(70 \%)$ than in life in general. There are many possible reasons, for example, it may be because people usually spend more time at work than other parts of your life. The high level of participation could be achieved only in the workplace, where there is a shared sense of destiny and purpose, which connects to people on an emotional level, and raise their aspiration.(Holbeche and Springett, 2003).

\section{Lighting}

Lighting is directly related to performance level of employs since there is a significant relationship between lighting system, eyes, headache and nervousness complaints while having energy conservation with suitable lighting system, the economic benefits of energy such as reduced glare and right illumination intensity is compensated with energy-cost saving (Sullivan, E, 1995) (Ertugrul Tarcan and Ergin Sait Varol, 2004) According to study of

\begin{tabular}{llll|l}
\hline JISR-MSSE & Volume 14 & Number 1 & Jan-June 2016 & 65
\end{tabular}


Lawrence Berkley (Ertugrul Tarcan and Ergin Sait Varol, 2004) laboratory in California, 30$35 \%$ of energy consumed in commercial building is used for lighting. Concern for how lighting influences the state of the worker has centered on the effects of specific factors such a as glare contrast \& Spectral distribution on visual comfort (Guth, S.K,, 1970) (Hopkinson, R.G, 1969) (IES, 1972) (Robert I. Sutton and Anat Rafaeli, 1987) found that the feeling of well-bring was optimal at intermediate illuminances even through recognition time was best at the highest illuminances. In contract of to this (Flynn 1977) reported that relatively low background illumination is acceptable \& more restful for office workers. There is an agreement among scholars that high levels of glare, lack of natural light and levels of lighting, that are too low, for a given task, can have negative effects on performance \& well-being (Greg R. Oldham and Nancy L. Rotchford, 1983)found a negative relationship b/w darkness and employee's reactions including satisfaction with work, the presence of personal items in the work station \& discretionary time spend in the work station.

\section{Acoustics}

Exposure to occupational noise is associated with a verity of adverse effects including hearing loss (Johnson \& Evans, 2000) (LucySullivan, DianeBeale, \& PhilLeather, 2003) and physical health problems likes cardiac problems (Jansen,G, 1983) (LucySullivan, DianeBeale, \& PhilLeather, 2003)sickness-related absenteeism (Cohen A, 1973) (LucySullivan, DianeBeale, \& PhilLeather, 2003) and self reported fatigue (Carlestam,G.,Karlsson,C.,\&Levi,L, 1973) (LucySullivan, DianeBeale, \& PhilLeather, 2003). The reasons behind this noise are 1) Telephones ringing and from type writers 2) Piped in back ground music (Sundstrom,E.,Town,J.P.,Rice,R.W.,Osborn,D.P.,\&Brill, M, 1994) (LucySullivan, DianeBeale, $\&$ PhilLeather, 2003).In contrast to it, the present study shows that no direct effect of ambient noise level upon job satisfaction, well-being or organizational commitment. However, lower level of ambient noise was found to buffer the negative impact of psychosocial job stress (LucySullivan, DianeBeale, \& PhilLeather, 2003).

\section{Furniture and Tools}

There is a direct relation between comfort level provided to employees and productivity of that organization. If employs are facilitated with good furniture \& tools such as armchairs, desks, computers and best fitting apparatus then it leads to increase in performance level of employs and consequently progress of that company "The negative effects of deferred maintenance and or investment due to lack of funds can result losses to building owners and health hazards to users. (Shen, Q., Lo, K.K. and Wang, Q., 1996) (Ertugrul Tarcan and Ergin Sait Varol, 2004).

\section{Building's General Environment}

Building's general environment should be good since it is related to employee's emotional health, and same can also accelerated performance level of employees. "Investment made by the company to foster safety cultures in their organizations may reduce personal injury" (KathrynMearns, SeanM.Whitaker RhonaFlin, 2003) and as a consequence, it can promote loyalty. The study of the effect of office design on the members of the organization is one of the most neglected areas in the field of organizantion behaviours (Manning, Peter, 1965) (Steele, Fred I, 1973) (Becker, Franklin D, 1973) (Greg R. Oldham and Nancy L. Rotchford, 1983).

\begin{tabular}{l|lll}
\hline 66 & Jan-June 2016 & Volume 14 & Number 1
\end{tabular}


The instrusions from work station can be categorized as

1) Instrusions from atomospheric condition (including temperature, Openess, Architectural accessibility,Darkness)

2) Instrusions associated reaction of employees (Noise \& with distraction, Density, Control over privacy).

Instrusions from atmospheric conditions \& instrusions from other employees were not consistently related to negative reactions. However, instrusions were more strongly associated with reaction to employee's work stations than with general reactions to their work. Employees reporting high overload, had relatively fewer negative reactions to otness and density. (Robert I. Sutton and Anat Rafaeli, 1987). This refers to the overall openness of the office, more specifically, to the ratio of total square footage of the office to the total length of its interior walls and partitions (Guide to the Paul V. Gump Collection, 1977) (Greg R. Oldham and Nancy L. Rotchford, 1983). If square footage is kept constant, then offices with few interior boundaries are considered more open than offices with many walls and partitions.

This refers to the number of open area feet available to an employee in the office (Stokols Daniel, 1972), (Schmidt, Donald E. and John P. Keating, 1979),(Greg R. Oldham and Nancy L. Rotchford, 1983).Offices are solid to the scope that a large number of employees work in a comparatively small area or space. This refers to the extent to which an employee's individual workspace (e.g., desk) is accessible to the external intrusions of others. In this study, workspaces that were surrounded by walls or partitions were considered inac- cessible, since physical boundaries would limit, to some de- gree, behavioral and visual intrusions (Archea, John, 1977 ) (Greg R. Oldham and Nancy L. Rotchford, 1983). Dark offices are here defined as those that have both low levels of illumination and darkcolored walls (Greg R. Oldham and Nancy L. Rotchford, 1983).

\section{Research Model}

This model is adapted from (Makhbul, Zafir Mohd, 2013)

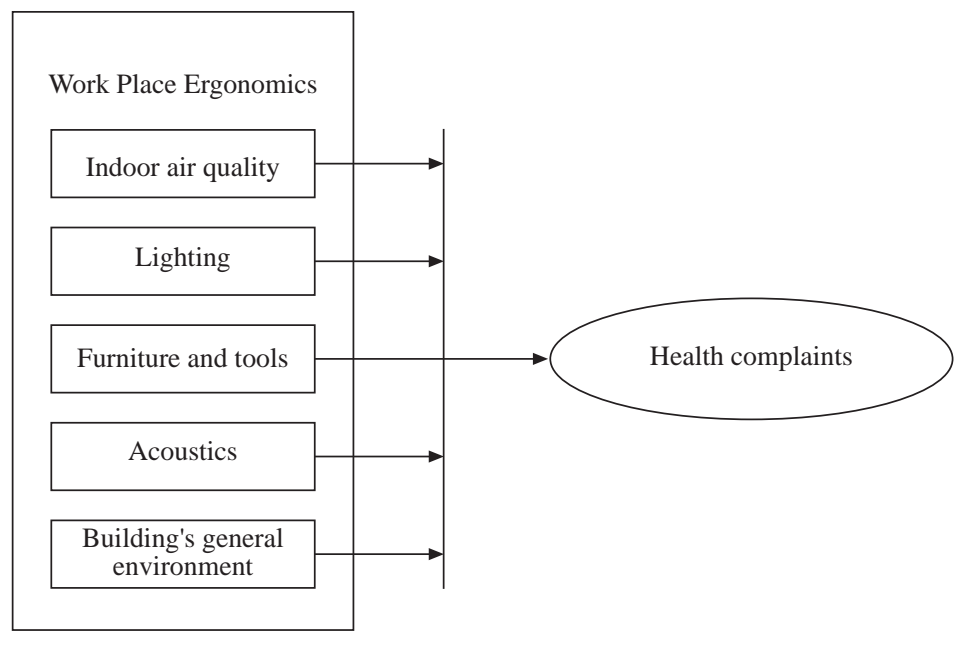




\section{Research Methodology}

Details of Research methodology is as follows containing the design, sampling, technique, instruments, Hypothesis and analysis plan.

\section{Population and Sample}

The goal of this study is to achieve the suitable option and highlight the employees' problem in the work place of textile industry. With the help of survey data we can easily find out the behavior, health, and environmental impacts on employees. In this manner we selected four different textile companies, two local and two multinational. We have distributed 200 questioners' papers and we got 133 filled questioners. These questioners were distributed in different department of textile industries. In questioners we have added best suitable parameter according to textile industry these includes are temperature, noise, safety, light, working environment \& chemical hazards in textile industry.

We selected our best points which we finalized through sample technique and collected data from them. Our participants as respondent has different designations, qualifications, nature of work and departments including males and females which are as follows:

- Head of departments (Quality, Technical Transfer, Business Development and Regulatory Affairs, Finance, Marketing, etc.)

- Managers of departments (Marketing, Sales, Production, IT, Services, Supply Chain Management, Strategic Management, Training \& Development, Sales Force Excellence, Sales etc.)

- Assistant Managers and Executives of different departments (Regulatory Affairs, Sales Force Support, Key Account Management, Finance, Sales etc.)

- Officers of different departments (Procurement, Sales, administration etc.)

- Labor (Production, Quality Assurance, Packaging etc.)

\section{Investigation Technique}

We used technique of primary data collection with the help of questionnaire. Close ended type questionnaire with the approach of Likert scaling was prepared for the collection of data.

Scaling is consisted on following options:

1-5 (1 = Your Lowest agreement and $5=$ Your Highest Agreement $)$

\section{Instrumentation}

In our questionnaire, we are using dependent, independent and demographic variables which are collected from reference articles:

- Health Complains- Dependent

- Workplace Environment - Independent (Latent Variables)

\begin{tabular}{l|llll}
\hline 68 & Jan-June 2016 & Volume 14 & Number 1 & JISR-MSSE
\end{tabular}


Lighting as an Independent (Latent Variables)

Furniture and tools as an Independent (Latent Variables)

Indoor air quality as an Independent (Latent Variables)

Acoustics as an Independent (Latent Variables)

Building's general environment as an Independent (Latent Variables)

- Demographic

n Gender

n Age

Education

months of working experience

n Working hour per week

Health Complains as an Dependent

Reference Article

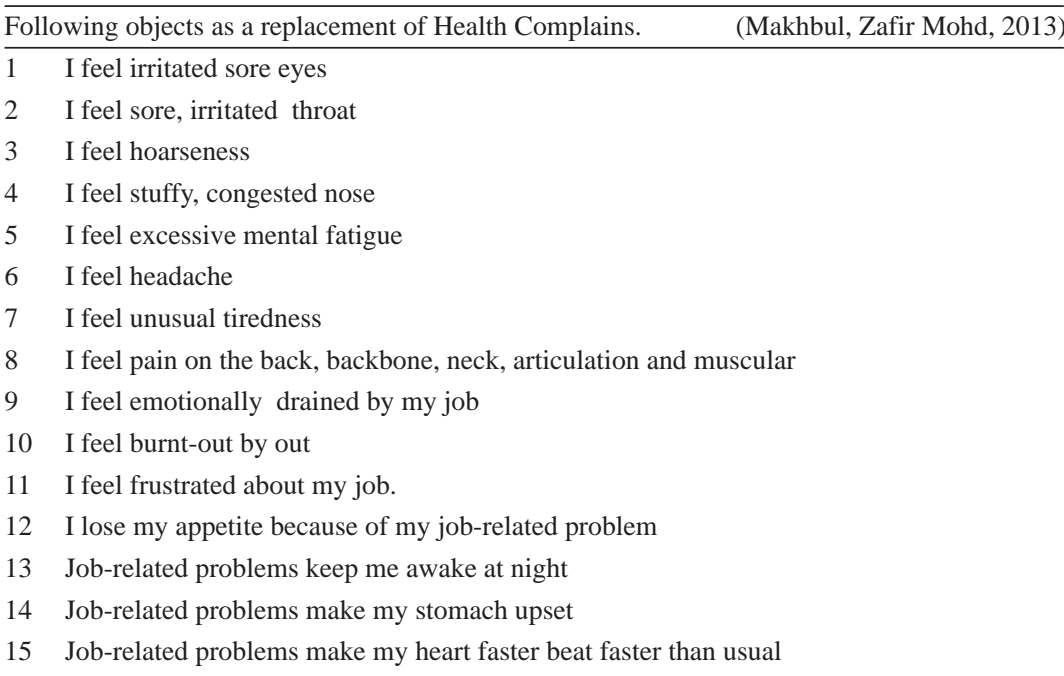

Lighting as an Independent

Reference Article

The following Items are showing to Lighting

1 I am satisfy with lighting system

2 Lighting system is flexible

3 Benefit of daylight is available

Furniture and tools as an Independent

Reference Article

The following Items are showing to Furniture and tools (Makhbul, Zafir Mohd, 2013)

1 You have suitable furniture/ tools

2 You have adjustable furniture/ tools

3 Enough human interaction and working equipment i.e. Updated Computer 


\begin{tabular}{ll}
\hline The following Items are showing to Indoor air quality & (Makhbul, Zafir Mohd, 2013) \\
\hline 1 & Indoor temperature is too cold \\
2 & Indoor temperature is too warm \\
3 & Too little indoor air movement \\
4 & Indoor air too dry \\
5 & Unpleasant odor in internal air \\
6 & Internal air is not fresh \\
7 & Indoor air is too dusty \\
\hline
\end{tabular}

\begin{tabular}{llr} 
Acoustics as an Independent & Reference Article \\
\hline The following Items are showing to Acoustics & (Makhbul, Zafir Mohd, 2013) \\
\hline 1 & No internal noise/sound problem & \\
2 & No external noise/sound problem & \\
3 & Your organization has done study to know the organizational noise level \\
4 & study acceptable noise level done & Reference Article \\
\hline & & Makhbul, Zafir \\
Building's general environment as an Independent & Mohd, 2013) \\
\hline The following Items are showing to Building's general environment & \\
\hline 1 & healthy work environment & \\
2 & safe work environment & \\
3 & building effect on performance & \\
4 & building effect on image & \\
5 & building support social activity & \\
6 & building cleanliness
\end{tabular}

\section{Data Collection Method}

The data, which is collected in survey research, is primary data. Research will be carried out by conducting personal interview through structured questionnaire. 


\section{Data Analysis Plan}

To verify effects of Multiple Linear Regression we used through SPSS for Data Analysis Plan.

Cronbach's coefficient alpha used to check the reliability and results are as follows:

Table.1

\begin{tabular}{lcc}
\hline Reliability Statistics & & \\
\hline & Cronbach's Alpha & No of Items \\
Health Complains: & 0.889 & 15 \\
Indoor air quality: & 0.410 & 7 \\
Lighting: & 0.480 & 3 \\
Furniture and tools: & 0.616 & 3 \\
Acoustics: & 0.654 & 4 \\
Building's general environment: & 0.577 & 6 \\
\hline Source: $E$ Views 8 & &
\end{tabular}

\section{RESULT AND DISCUSSIONS}

\section{Regression}

\begin{tabular}{|c|c|c|c|c|c|}
\hline \multirow[b]{2}{*}{ Table.2 } & \multicolumn{5}{|c|}{ Model Summary } \\
\hline & Model & $\mathrm{R}$ & R Square & Adjusted R Square & Std. Error of the Estimate \\
\hline & 1 & $.504 a$ & .254 & .224 & .68786 \\
\hline & 2 & $.504 \mathrm{~b}$ & .254 & .231 & .68517 \\
\hline & 3 & $.504 \mathrm{c}$ & .254 & .236 & .68252 \\
\hline
\end{tabular}

a. Predictors: (Constant), Building Environment, IAQ, Lighting, Acoustics, Furniture and tools

b. Predictors: (Constant), Building Environment, IAQ, Acoustics, Furniture and tools

c. Predictors: (Constant), Building Environment, IAQ, Acoustics

$\mathrm{R}$ is defining the strong relationship in Model Summary

ANOVA $^{d}$

\begin{tabular}{|c|c|c|c|c|c|c|c|}
\hline \multirow[b]{2}{*}{ Table.3 } & \\
\hline & Model & Sum of Squares & Df & Mean Square & $\mathrm{F}$ & Sig. & \\
\hline & \multirow[t]{3}{*}{1} & Regression & 20.442 & 5 & 4.088 & 8.641 & $.000 \mathrm{a}$ \\
\hline & & Residual & 60.091 & 127 & .473 & & \\
\hline & & Total & 80.533 & 132 & & & \\
\hline & \multirow[t]{3}{*}{2} & Regression & 20.442 & 4 & 5.111 & 10.886 & $.000 \mathrm{~b}$ \\
\hline & & Residual & 60.091 & 128 & .469 & & \\
\hline & & Total & 80.533 & 132 & & & \\
\hline & \multirow[t]{3}{*}{3} & Regression & 20.440 & 3 & 6.813 & 14.626 & $.000 \mathrm{c}$ \\
\hline & & Residual & 60.093 & 129 & .466 & & \\
\hline & & Total & 80.533 & 132 & & & \\
\hline
\end{tabular}

\begin{tabular}{llll|l}
\hline JISR-MSSE & Volume 14 & Number 1 & Jan-June 2016 & 71
\end{tabular}


a. Predictors: (Constant), Building Environment, IAQ, Lighting, Acoustics, Furniture and tools

b. Predictors: (Constant), Building Environment, IAQ, Acoustics, Furniture and tools

c. Predictors: (Constant), Building Environment, IAQ, Acoustics

d. Dependent Variable: Health complaint

As per above table of ANOVA. Sig value is mentioning .000 which means that the model is significant

Coefficients $^{\mathrm{a}}$

\begin{tabular}{|c|c|c|c|c|c|c|}
\hline \multirow{2}{*}{ Model } & \multicolumn{2}{|c|}{ Unstandardized Coefficients } & \multicolumn{4}{|c|}{ Standardized Coefficients } \\
\hline & B & Std. Error & Beta & & $\mathrm{t}$ & Sig. \\
\hline \multirow[t]{6}{*}{1} & (Constant) & 2.739 & .475 & & 5.766 & .000 \\
\hline & IAQ & .488 & .112 & .345 & 4.366 & .000 \\
\hline & Lighting & .001 & .088 & .001 & .014 & .989 \\
\hline & Furniture and tools & -.005 & .081 & -.006 & -.063 & .950 \\
\hline & Acoustics & -.165 & .083 & -.178 & -1.979 & .050 \\
\hline & Building Environment & -.279 & .102 & -.242 & -2.728 & .007 \\
\hline \multirow[t]{5}{*}{2} & (Constant) & 2.740 & .466 & & 5.880 & .000 \\
\hline & IAQ & .488 & .111 & .345 & 4.387 & .000 \\
\hline & Furniture and tools & -.005 & .077 & -.005 & -.062 & .951 \\
\hline & Acoustics & -.165 & .082 & -.178 & -2.006 & .047 \\
\hline & Building Environment & -.279 & .099 & -.242 & -2.818 & .006 \\
\hline \multirow[t]{4}{*}{3} & (Constant) & 2.730 & .434 & & 6.295 & .000 \\
\hline & IAQ & .490 & .108 & .346 & 4.545 & .000 \\
\hline & Acoustics & -.167 & .078 & -.180 & -2.149 & .034 \\
\hline & Building Environment & -.280 & .097 & -.243 & -2.900 & .004 \\
\hline
\end{tabular}

a. Dependent Variable: Health complaint

Above table is representing the following understandings:

\section{Model 1:}

\section{Model one represents that,}

1. Lighting is not affecting very much if more do efforts on Health complaint.

2. Furniture and tools is also not affecting sufficient for Health complaint.

3. Building Environment is also not affecting sufficient for Health complaint.

4. In Indoor air quality we can say that if change from 1 then as per Beta, .488 per unit change will occur as improvement in Health complaint.

5. In Acoustics we can say that if change from 1 then as per Beta, -.165 per unit change will occur as improvement in Health complaint.

\begin{tabular}{l|lll}
\hline 72 & Jan-June 2016 & Volume 14 & Number 1
\end{tabular}




\section{Model 2:}

\section{Model three represents that,}

1. Furniture and tools is also not affecting sufficient for Health complaint.

2. Building Environment is also not affecting sufficient for Health complaint.

3. In Indoor air quality we can say that if change from 1 then as per Beta, .488 per unit change will occur as improvement in Health complaint.

4. In Acoustics we can say that if change from 1 then as per Beta, -.165 per unit change will occur as improvement in Health complaint.

\section{Model 3:}

\section{Model three represents that,}

1. In Indoor air quality we can say that if change from 1 then as per Beta, .490 per unit change will occur as improvement in Health complaint.

2. In Acoustics we can say that if change from 1 then as per Beta, -.167 per unit change will occur as improvement in Health complaint.

3. In Building Environment we can say that if change from 1 then as per Beta, -.280 per unit change will occur as improvement in Health complaint.

\begin{tabular}{|c|c|c|c|c|}
\hline Sr. No. & Hypothesis & $\mathrm{t}$ & Sig. & Accept/Reject \\
\hline 1 & Indoor air quality has significant positive & & & \\
\hline & impact in employee health complaints. & 4.545 & .000 & Accept \\
\hline 2 & $\begin{array}{l}\text { Lighting has significant positive impact in } \\
\text { employee health complaints. }\end{array}$ & .014 & .989 & Fail to Reject \\
\hline 3 & $\begin{array}{l}\text { Furniture and tools has significant positive } \\
\text { impact in employee health complaints. }\end{array}$ & -.062 & .951 & Fail to Reject \\
\hline 4 & $\begin{array}{l}\text { Acoustics has significant positive impact in } \\
\text { employee health complaints. }\end{array}$ & -2.149 & .034 & Accept \\
\hline 5 & $\begin{array}{l}\text { Building's general environment has } \\
\text { significant positive impact in }\end{array}$ & & & \\
\hline & employee health complaints. & -2.900 & .004 & Accept \\
\hline
\end{tabular}

\section{CONCLUSION, LIMITATION, \& RECOMMENDATION}

This research is focused on textile Industry with special reference to the area of Karachi and we analyzed the impacts on Employees job. The findings showed that among all factors \& health safety is the core element that is affecting on Job Satisfaction and required more concentrate. We recommend adopting best suitable and healthful environment for Employee. 
i.e. noise \& hazards free, work place satisfaction, lighting, Acoustics \& more efficiently to increase the level of satisfaction for employees that will resulted in overall better business performance, will make loyalty from employees towards the organizations and create a feeling of job satisfaction.

\section{LIMITATION AND FUTURE RESEARCH}

This study tools is to achieve the fulfillment for the workplace environment of Karachi textile industry. Due to the shortage of time and cost we have done only Karachi textile industry. This is also helpful for implementation of internal checks and deployment of better rules and regulation for textile industry to indoor quality, health complains light etc. In future studies; we will add some more points related to the generator noise, electricity shortage and fumes of hazardous chemical in the environment of textile industry.

\section{REFERENCES}

Annet H de Lange, Toon W Taris, Michiel AJ Kompier, Irene LD Houtman, Paulien M Bongers. (2002). Effects of stable and changing demand-Control Histories on worker health. Scand J work Environ Helth , 2 (28), 94-108.

Archea, John. (1977 ). The place of architectural factors in behavioral theories of privacy. Journal of Social Issues , 33, 116-137.

Becker, Franklin D. (1973). Study of spatial markers. Journal of Personality and So- cial Psychology , 26, 439-445.

Carlestam,G.,Karlsson,C.,\&Levi,L. (1973). Stress and diseasein response to exposure to noise: a review. In W. Ward. Proceedings of the second international congress on noise as a public health problem , 9 (73), 479-486.

Cohen A. (1973). Industrial noise and medical, absence, and accident record data on exposed workers. In W. Ward (Ed.), Proceedings of the second International Congress on noise as public health problem,. DC:EPA (pp451-454).

Dalbokova, D. and Krzyzanowski, M. (2002). Environmental health indicators: development of amethodology for the who European region. Statistical Journal of the UN Economic Commission for Europe, 19, 93-103.

Ertugrul Tarcan and Ergin Sait Varol. (2004). A qualitative study of facilities and their environmental. Marmar a University, Istanbul, Turkey , 15 (2), 154-173.

Feare, T. (2001). Demystifying ergonomics, Modern Material Handling,. 56, 39-41.

Ghulam Muhammad,Ubedullah Memon. (2012). Determinants of Employee Motivation- A Case Study of Afroz textile Industries Limited, Karachi, Pakistan. IOSR Journal of Business and management , 4 (3), 22-25.

\begin{tabular}{l|llll}
74 & Jan-June 2016 & Volume 14 & Number 1
\end{tabular}


Greg R. Oldham and Nancy L. Rotchford. (1983). Relationships between Office Characteristics and Employee Reactions: A Study of the Physical Environment. 28, 542-556.

Guide to the Paul V. Gump Collection. (1977). What's happened in schools. Unpublished manuscript, Department of Psychology, University of Kansas .

Guth, S.K,. (1970). Lighting for visual performance and visual comfort. journal of the Americcan optometric Association , 41, 63-71.

Hopkinson, R.G. (1969). Lighting and seeing. London: Heineman .

IES. (1972). Outline of a standard procedure for computing visual comfort ratings for interior lighting. journal of the Illuminationg Engineering Society , 2, 328-344.

J K Sluiter. E M de Croon, T F Meijman, M H W Frings-Dresen. (2003). Need for recovery from work related fatigue and its role in the development and prediction of subjective health complaints. Coronel Insitute For Occupational and Environmental Health, $60, \mathrm{i} 62-\mathrm{i} 70$.

Jagdish K.Dua. (1994). Job Stressors and Their Effects on Physical Health, Emotional Health, and Job Satisfaction in a University. Journal of Educational , 32 (0957-8234), 59-78.

Jansen,G. (1983). Adverse effects of noise on iron an dsteel workers. Stahl Eisen. NewYork:Academicpress , 81, 217-220.

Johnson, D., \& Evans, G. W. (2000). The handbook of hearing and the effects of noise. AcademicPress. , 85(5) (779-783).

KathrynMearns, SeanM.Whitaker RhonaFlin. (2003). Safetyclimate, safety management practiceand safety performance ino?shore environments. ElsevierLtd, 41, 641-680.

LucySullivan, DianeBeale, \& PhilLeather. (2003). Noise, psychosocial stress and their in teraction in the workplace. Journal of Environmental Psychology, 23 (213-222).

Makhbul, Zafir Mohd. (2013). WorkPlace Enviroment towards Emotional Health. International Jouranaof Academic Research in Business and Social Science, 3 (1).

Manning, Peter. (1965). Office Design: A Study of Environment. Liverpool: University of Liverpool.

Martin, J. (1999). Addressing IAQ Concerns in Medical Facilities. Engineered Systems , 6, 53-57.

Paul H.P. Yeow. Rabindra Nath Sen. (2003). Quality, Productiviy, Occupational health and safety and cost effectiveness of ergonomic improvement in the test workstations of an electronic factory. International Journal of Industrial Ergonomics (32), 147-163. 
Peter Cotton, Peter M. HART. (2003). Occupational Wellbeing and performance: A review of Organisational Health Research. Australian Psychologist , 38, 118-127.

Robert I. Sutton and Anat Rafaeli. (1987). The Academy of Management Journal , 30, 260276.

Schmidt, Donald E. and John P. Keating. (1979). Human crowding and personal control: An integration of the research Psychological Bulle- tin. PsycARTICLES , 86, 680-700.

Shen, Q., Lo, K.K. and Wang, Q. (1996). Priority setting in maintenance management: a modi?ed multi-attribute approach using analytic hierarchy process", Construction Management and Economics. IOSR JOURNALS, 6, 693-702(10).

Steele, Fred I. (1973). Physical Settings and Organiza- tion Development. Reading.

Stokols Daniel. (1972). On the distinction between density and crowding: some implications for future research. Psychological Review , 79, 275-277.

Sullivan, E. (1995, August). Productivity building operating management. www.facilitiesnet.com/fn/NS/NS2prodo.html.

Sundstrom,E.,Town,J.P.,Rice,R.W.,Osborn,D.P.,\&Brill, M. (1994). Of?ce noise, satisfaction and performance. Environment \& Behavior, 26 (2), 195-222.

\begin{tabular}{l|llll}
\hline 76 & Jan-June 2016 & Volume 14 & Number 1
\end{tabular} 


\section{Appendix: Questionnaire}

Dear Respondent,

You are kindly requested to respond to the statements in the following questionnaire.

The statements are related to the Workplace Environment in Karachi Textile Industry towards Emotional Health.

Your responses are of great importance as this survey forms part of a study of the aspect mentioned above. I therefore value your co-operation very highly.

On the following pages you will find a shortlist of questions.

Please check mark $(\checkmark)$ to the answer that you think is the most suitable.

It should not take you more than 10-15 minutes to complete the entire questionnaire. Please ensure that you respond to every question.

I am strongly interest in your personal opinion. The "right" answer to any question is your frank and truthful response.

Your answer will be treated as Strictly Confidential and will only be used for research purposes. Your name should not appear anywhere on this document.

Please turn to the next page.

Your answer $(\checkmark)$ required between 1-5 $(1=$ Your Lowest agreement and $5=$ Your Highest Agreement $)$

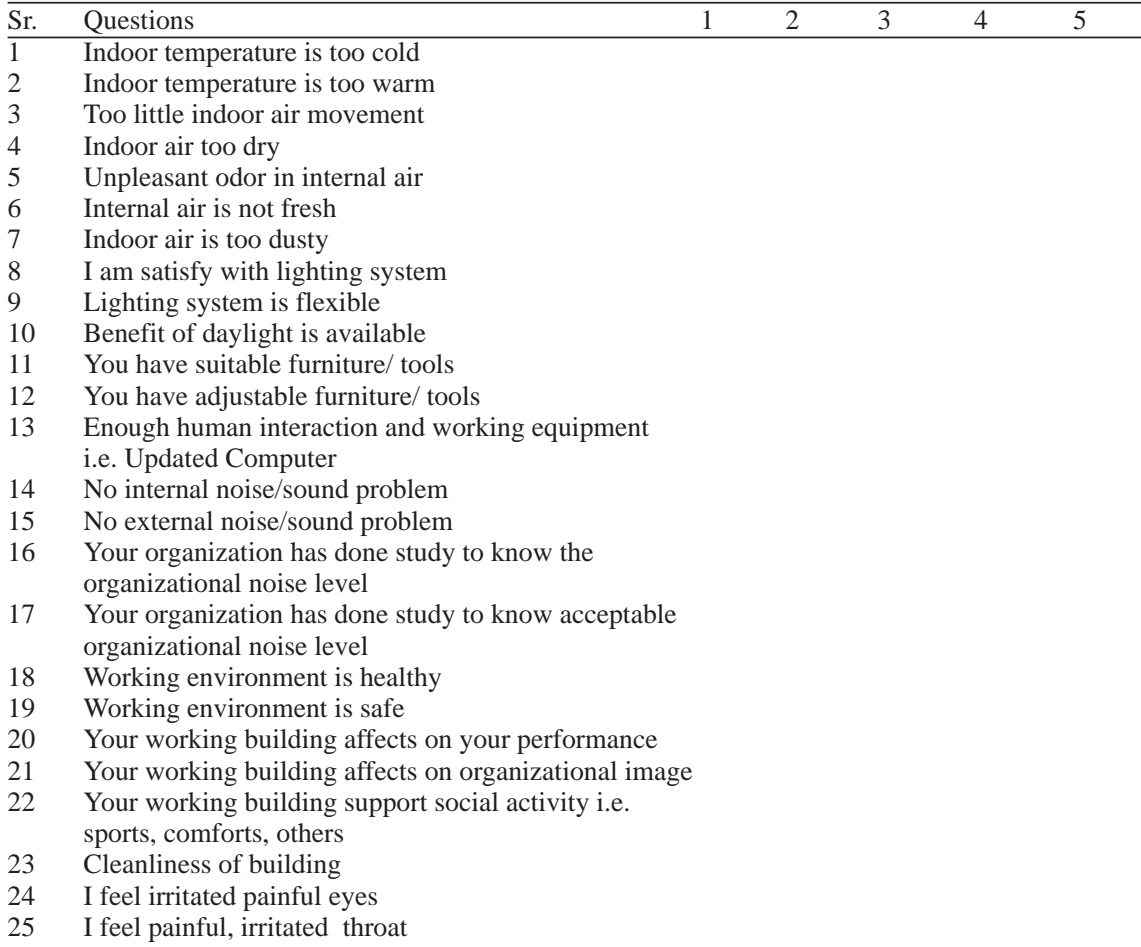


26 I feel harshness/hoarseness

27 I feel stuffy, congested nose

28 I feel too much mental fatigue

29 I feel headache

30 I feel unusual tiredness

31 I feel pain on the back, backbone, neck, articulation and muscular

32 I feel emotionally exhausted by my job

33 I feel burnt-out by out

34 I feel frustrated about my job.

35 I lose my appetite because of my job-related problem

36 Job-related problems keep me awake at night

37 Job-related problems make my stomach upset

38 Job-related problems make my heart faster beat faster than usual

39 Gender

40 Your Age

$<25 \quad 25-30 \quad 31-35 \quad 36-40 \quad 40>$

Your Education

Your total years/months of working experience

Working hour per week

$<39 \quad 40-49 \quad 50-59 \quad 60-69 \quad 69>$

Thank you very much to answer on above questionnaire.

Page No. 